\title{
Comunicação
}

[Communication]

\section{Deteç̧ão da resistência a antibióticos de bactérias isoladas de casos clínicos ocorridos em animais de companhia}

\author{
[Detection of antibiotic resistance in clinical bacterial strains from pets] \\ P. Poeta, J. Rodrigues \\ CECAV- Departamento de Ciências Veterinárias \\ Universidade de Trás-os-Montes e Alto Douro \\ Apart. 1013 \\ 5000-911 - Vila Real, Portugal
}

\begin{abstract}
Existem inúmeras espécies bacterianas relacionadas com infecções em clínica de pequenos animais. Por outro lado, microrganismos comensais podem, em certas circunstâncias, ser responsáveis por processos infecciosos, tornando-se necessário proceder à administração de agentes antimicrobianos como forma de limitar o avanço da infecção. A comunidade científica tem manifestado, nos últimos anos, preocupação em relação à resistência aos antibióticos devido às graves conseqüências, no tratamento de doenças infecciosas, que essa questão pode acarretar (Poeta et al., 2005). Várias publicações científicas relatam a relação entre os antibióticos usados em animais e o aparecimento de resistências em estirpes bacterianas de importância em patologia humana e animal (Piddock, 1996; Witte, 1998; Torres e Zarazaga, 2002; Carneiro et al., 2007; Macedo et al., 2007). Como resultado da exposição aos antibióticos, o grau de resistência das bactérias, que pertencem à flora intestinal normal de humanos e animais, pode aumentar. Essas bactérias constituem um reservatório de genes de resistência para microrganismos patogênicos. $\mathrm{O}$ nível de resistência na flora endógena é considerado um bom indicador da pressão selectiva exercida pelo uso de antibióticos nessa população e para os problemas de resistência esperados nos agentes patogênicos.
\end{abstract}

A existência de estirpes bacterianas, comensais ou patogênicas, causadoras ou relacionadas com

Recebido em 1 de fevereiro de 2007

Aceito em 29 de março de 2008

E-mail: ppoeta@utad.pt determinadas infecções, com fenótipos de resistência a várias classes de antibióticos, tornase, várias vezes, um grave problema em clínica de pequenos animais, visto que esta situação deixa poucas hipóteses de tratamento desses animais.

Com o objetivo de isolar estirpes bacterianas e estudar a sensibilidade aos antibióticos, foram utilizados 52 animais de companhia (37 cães e 15 gatos) com diferentes processos infecciosos; 15 casos de feridas e abscessos cutâneos, 10 de infecções do aparelho respiratório, oito de otites, sete de infecções do aparelho urinário, seis de mamites e seis de infecções oculares. As amostras - exsudado purulento, fluido broncoalveolar, cerumen auricular, urina, líquido mamário e exsudado ocular - foram semeadas em ágar sangue ${ }^{1}$, ágar nutritivo ${ }^{1}$, ágar MacConkey ${ }^{1} \mathrm{e}$ caldo $\mathrm{BHI}^{2}$ e incubadas à temperatura de $37^{\circ} \mathrm{C}$, durante 24-48 horas. As amostras de exsudado purulento foram, adicionalmente, semeadas em meio de Cooked-meat ${ }^{2}$. Após o período de incubação, as colônias suspeitas em cada placa de ágar foram, posteriormente, repicadas em agar $\mathrm{BHI}^{2}$ e incubadas durante 24 horas, à temperatura de $37^{\circ} \mathrm{C}$. As colônias isoladas foram coradas pelo Gram, e submetidas às provas da catalase, da oxidase $\mathrm{e}$ da coagulase. A identificação dos isolados até a espécie foi realizada por meio dos sistemas de identificação API $20 \mathrm{E}^{3}$ e API $20 \mathrm{NE}^{3}$. Streptococcus spp. e Staphylococcus spp. foram classificados até gênero. $O$ ensaio da sensibilidade aos antibióticos foi realizado pelo método de difusão

\footnotetext{
${ }^{1}$ Merck - Portugal

${ }^{2}$ Difco - Portugal

${ }^{3}$ Oxoid - Portugal
} 
em ágar ou técnica de Kirby-Bauer, com os seguintes antibióticos em disco ${ }^{4}$ : amoxicilina+ácido-clavulânico $\quad(30 \mu \mathrm{g})$, oxitetraciclina $(30 \mu \mathrm{g})$, enrofloxacina $(5 \mu \mathrm{g})$, ciprofloxacina $(5 \mu \mathrm{g})$, amoxicilina $(10 \mu \mathrm{g})$, ampicilina $(10 \mu \mathrm{g})$, cefoperazona $(30 \mu \mathrm{g})$, cefradina $(30 \mu \mathrm{g})$, cefotaxima $(30 \mu \mathrm{g})$, ceftriazona $(30 \mu \mathrm{g})$, neomicina $(10 \mu \mathrm{g})$, estreptomicina $(10 \mu \mathrm{g})$, gentamicina $(10 \mu \mathrm{g})$, metronidazol
$(50 \mu \mathrm{g})$, colistina $(10 \mu \mathrm{g})$ e trimetoprimsulfametoxazol $(25 \mu \mathrm{g})$.

Os gêneros Streptococcus spp. e Staphylococcus spp. foram os mais freqüentemente isolados das diferentes amostras analisadas. As espécies bacterianas isoladas dos diferentes processos infecciosos manifestaram resistência a uma grande diversidade de agentes antimicrobianos usados como rotina em clínica (Tab. 1).

Tabela 1. Resistência a antibióticos de espécies bacterianas isoladas de amostras clínicas de 52 animais de companhia

\begin{tabular}{|c|c|c|c|c|c|c|c|c|c|c|c|c|c|}
\hline \multirow{2}{*}{$\begin{array}{l}\text { Amostra } \\
\left(\mathrm{N}^{\mathrm{o}} \text { animais }\right)\end{array}$} & \multirow{2}{*}{ Espécies isoladas $\left(\mathrm{N}^{\circ}\right)$} & \multicolumn{12}{|c|}{ \% Resistência aos antibióticos } \\
\hline & & 1 & 2 & 3 & 4 & 5 & 6 & 7 & 8 & 9 & 10 & 11 & 12 \\
\hline Epur (15) & \begin{tabular}{|l|} 
Staphylococcus spp.(4) \\
Streptococcus spp.(4) \\
Proteus mirabilis (3) \\
Proteus vulgaris (2) \\
Serratia marcencens (2)
\end{tabular} & \begin{tabular}{|c|}
75 \\
50 \\
100 \\
50 \\
100 \\
\end{tabular} & \begin{tabular}{|c|}
- \\
- \\
33 \\
- \\
100 \\
\end{tabular} & \begin{tabular}{|c|}
- \\
50 \\
- \\
50 \\
-
\end{tabular} & $\begin{array}{c}25 \\
- \\
66 \\
- \\
100\end{array}$ & \begin{tabular}{|c|}
25 \\
- \\
- \\
- \\
- \\
\end{tabular} & \begin{tabular}{c|}
25 \\
50 \\
66 \\
- \\
- \\
\end{tabular} & $\begin{array}{c}- \\
- \\
100 \\
- \\
-\end{array}$ & $\begin{array}{c}- \\
- \\
100 \\
- \\
-\end{array}$ & $\begin{array}{l}- \\
- \\
- \\
-\end{array}$ & $\begin{array}{l}- \\
- \\
- \\
- \\
-\end{array}$ & $\begin{array}{c}25 \\
50 \\
100 \\
- \\
- \\
\end{array}$ & \begin{tabular}{|c|}
25 \\
- \\
100 \\
- \\
100 \\
\end{tabular} \\
\hline Fba (10) & \begin{tabular}{|l} 
Pasteurella multocida (4) \\
Staphylococcus spp. (2) \\
Streptococcus spp. (2) \\
Escherichia coli $(2)$
\end{tabular} & \begin{tabular}{c|}
100 \\
- \\
100 \\
100
\end{tabular} & \begin{tabular}{|c|}
- \\
- \\
100 \\
100 \\
\end{tabular} & $\begin{array}{l}- \\
- \\
- \\
-\end{array}$ & $\begin{array}{c}100 \\
100 \\
100 \\
- \\
\end{array}$ & \begin{tabular}{|c|}
- \\
- \\
- \\
100 \\
\end{tabular} & \begin{tabular}{|c|}
- \\
- \\
- \\
100 \\
\end{tabular} & \begin{tabular}{|c|}
- \\
100 \\
100 \\
100 \\
\end{tabular} & $\begin{array}{c}- \\
100 \\
- \\
-\end{array}$ & \begin{tabular}{|c|}
- \\
- \\
- \\
100
\end{tabular} & $\begin{array}{l}- \\
- \\
- \\
-\end{array}$ & \begin{tabular}{c|}
- \\
- \\
50 \\
-
\end{tabular} & $\begin{array}{c}100 \\
50 \\
50 \\
100 \\
\end{array}$ \\
\hline Cauric (8) & $\begin{array}{l}\text { Staphylococcus spp. (6) } \\
\text { Proteus mirabilis (2) }\end{array}$ & \begin{tabular}{|c|}
50 \\
100 \\
\end{tabular} & \begin{tabular}{|c|}
50 \\
100 \\
\end{tabular} & \begin{tabular}{|c|}
- \\
100 \\
\end{tabular} & $\begin{array}{l}- \\
-\end{array}$ & - & \begin{tabular}{|c|}
50 \\
100 \\
\end{tabular} & \begin{tabular}{|c|}
- \\
100 \\
\end{tabular} & \begin{tabular}{l|l}
50 \\
- \\
\end{tabular} & $\begin{array}{l}- \\
-\end{array}$ & $\begin{array}{l}- \\
-\end{array}$ & \begin{tabular}{|c|}
50 \\
100 \\
\end{tabular} & $\begin{array}{l}50 \\
- \\
\end{array}$ \\
\hline Urina (7) & $\begin{array}{l}\text { Streptococcus spp. (4) } \\
\text { Escherichia coli (3) }\end{array}$ & \begin{tabular}{|c|}
- \\
66 \\
\end{tabular} & 33 & $\begin{array}{l}- \\
-\end{array}$ & \begin{tabular}{c|}
100 \\
33 \\
\end{tabular} & $\begin{array}{l}- \\
-\end{array}$ & \begin{tabular}{|c|}
100 \\
-
\end{tabular} & \begin{tabular}{|c|}
100 \\
- \\
\end{tabular} & \begin{tabular}{|c|}
100 \\
- \\
\end{tabular} & $\begin{array}{l}- \\
-\end{array}$ & $\begin{array}{l}- \\
- \\
\end{array}$ & \begin{tabular}{c|}
100 \\
-
\end{tabular} & $\begin{array}{l}100 \\
100 \\
\end{array}$ \\
\hline $\operatorname{Lmam}(6)$ & $\begin{array}{l}\text { Staphylococcus spp. (2) } \\
\text { Streptococcus } \text { spp. (2) } \\
\text { Escherichia coli }(2)\end{array}$ & \begin{tabular}{|c|}
100 \\
50 \\
50 \\
\end{tabular} & \begin{tabular}{|c|}
50 \\
- \\
50 \\
\end{tabular} & $\begin{array}{c}- \\
- \\
50\end{array}$ & $\begin{array}{l}- \\
- \\
-\end{array}$ & $\begin{array}{l}- \\
- \\
-\end{array}$ & $\begin{array}{c}100 \\
- \\
-\end{array}$ & $\begin{array}{c}100 \\
- \\
- \\
\end{array}$ & \begin{tabular}{c|}
- \\
- \\
50
\end{tabular} & $\begin{array}{l}- \\
- \\
-\end{array}$ & $\begin{array}{l}- \\
- \\
-\end{array}$ & \begin{tabular}{c|}
50 \\
- \\
- \\
\end{tabular} & $\begin{array}{l}- \\
- \\
-\end{array}$ \\
\hline Eocular (6) & $\begin{array}{l}\text { Staphylococcus spp. (3) } \\
\text { Streptococcus spp. (3) }\end{array}$ & $\begin{array}{l}- \\
-\end{array}$ & $\begin{array}{l}- \\
-\end{array}$ & $\begin{array}{l}- \\
-\end{array}$ & $\begin{array}{l}- \\
-\end{array}$ & $\begin{array}{l}- \\
-\end{array}$ & $\begin{array}{l}- \\
-\end{array}$ & $\begin{array}{l}- \\
-\end{array}$ & $\begin{array}{l}- \\
-\end{array}$ & \begin{tabular}{|c|}
- \\
100
\end{tabular} & \begin{tabular}{l|}
- \\
100
\end{tabular} & $\begin{array}{l}- \\
-\end{array}$ & $\begin{array}{c}100 \\
-\end{array}$ \\
\hline
\end{tabular}

Uma amostra de Staphlylococcus spp. isolada de mamite em cadela foi resistente à ciprofloxacina e à cefoperazona (dados não apresentados). Sabe-se que o uso de antibióticos, com fins profiláticos ou terapêuticos, em veterinária contribui para a seleção de bactérias resistentes, portanto é necessária a colaboração entre diferentes profissionais na vigilância do uso racional de antibióticos, em todas as vertentes, de forma a controlar esse problema (Gold, 2001). Assim, a prescrição de agentes

${ }^{4}$ BioMerieux - Portugal antimicrobianos deve obedecer a regras como: escolher o antibiótico mais eficaz em função dos dados clínicos do paciente e da epidemiologia local; identificar a bactéria tendo em conta os dados microbiológicos e dosar o antibiótico de forma adequada para não haver nenhuma possibilidade de o agente patogênico desenvolver resistência (Moreillon, 2000).

Palavras-chave: animais de companhia, bactérias, resistência a antibióticos 


\title{
Poeta e Rodrigues
}

\begin{abstract}
The identification of different bacterial strains and the occurrence of antibiotic resistance were investigated in several infection processes of pets as skin abscess with purulent discharge, bronco alveolar fluid, earwax, urine, mammary, and eye fluid. Streptococcus spp. and Staphylococcus spp. were the most detected in the different samples. A high frequency of antimicrobial resistance has been observed and this could reflect the wide use of antimicrobials in pets, making the effectiveness of antibiotic treatment to become more complicated.
\end{abstract}

Keywords: pets, bacteria, antibiotic resistance

\section{AGRADECIMENTO}

Os autores agradecem à Sra. D. Fátima Fraga pela assistência laboratorial.

\section{REFERÊNCIAS BIBLIOGRÁFICAS}

CARNEIRO, D.O.; FIGUEIREDO, H.C.P.; PEREIRA JÚNIOR, D.J. et al. Perfil de sensibilidade a antimicrobianos bactérias isoladas em diferentes sistemas de cultivo de tilápia-do-nilo (Oreochromis niloticus). Arq. Bras. Med. Vet. Zootec., v.59, p.869-896, 2007.

GOLD, H.S. Vancomycin-resistant enterococci: Mechanisms and clinical observations. Clin. Infect. Dis., v.33, p.210-219, 2001.

MACÊDO, N.R.; MENEZES, C.P.L.; LAGE, A.P. et al. Detecção de cepas patogênicas pela PCR multiplex e avaliação da sensibilidade a antimicrobianos de Escherichia coli isoladas de leitões diarréicos. Arq. Bras. Med. Vet. Zootec., v.59, p.1117-1123, 2007.
MOREILlON, P. Moyens de défense des bactéries. Rev. Med. Suisse Romande, v.120, p.641-650, 2000.

PIDDOCK, L.J.V. Does the use of antimicrobial agents in veterinary medicine and animal husbandry select antibiotic resistant bacteria that infect man and compromise antimicrobial chemotherapy? J. Antimicrob. Chemother., v.38, p.1-3, 1996.

POETA, P.; COSTA, D.; RODRIGUES, J. et al. Study of faecal colonization by vanA-containing Enterococcus strains in healthy humans, pets, poultry and wild animals in Portugal. $J$. Antimicrob. Chemother., v.55, p.278-280, 2005.

TORRES, C.; ZARAZAGA, M. Antibióticos como promotores del crescimiento en animales. vamos por el buen camino? Gac. Sanit., v.16, p.109-112, 2002.

WITTE, W. Medical consequences of antibiotics use in agriculture. Science, v. 279, p.996-997, 1998. 